\title{
Nano-Metal Borides of Cobalt, Nickel and Copper
}

\author{
Al-Zain Omar Ali*, Al-Masoudi and Reem Soliyman
}

Department of Chemistry, Faculty of Science, King Abdulaziz University, Jiddah, Saudi Arabia

\begin{abstract}
The magnesiothermic reaction of $\mathrm{CoO}, \mathrm{NiO}$ with $\mathrm{B}_{2} \mathrm{O}_{3}$ and $\mathrm{Mg}$ yielded only $\mathrm{Co}_{3} \mathrm{O}_{4}$, NiO. Similarly, direct reaction of $\mathrm{CoO}, \mathrm{NiO}$ with elemental boron yielded $\mathrm{CoB}_{2} \mathrm{O}_{4}$ and $\mathrm{NiO}$ respectively. The reaction of $\mathrm{CoCl}_{2}, \mathrm{NiCl}_{2}$ with elemental boron yielded $\mathrm{Co}_{2} \mathrm{~B}, \mathrm{NiO}$ respectively. On the other hand direct reaction of pure $\mathrm{Co}$, Cu metal with elemental boron in $1: 1,1: 2$ and $1: 3$ ratios produced metal oxides except $1: 3$ ratio produced was $\mathrm{CoB}$ and $\mathrm{Cu}\left(\mathrm{BO}_{2}\right)_{2}$. So, Solid phase with metal oxides and chlorides ended with metal oxides except with cobalt oxide and elemental Boron where $\mathrm{CoB}_{2} \mathrm{O}_{4}$ was produced. Reacting pure metals and elemental boron produced nano-metal borides for $\mathrm{Co}, \mathrm{Ni}$ and $\mathrm{Cu}$. The liquid phase reaction of $\mathrm{CoCl}_{2}, \mathrm{NiCl}_{2}$ and $\mathrm{CuCl}_{2}$ with sodium borohydride, $\mathrm{NaBH}_{4}$, produced black nanocrystals and nanorods of $\mathrm{CoB}_{2} \mathrm{O}_{4}, \mathrm{Ni}_{4} \mathrm{~B}_{3}, \mathrm{CuB}_{24}$ and $\mathrm{CuO}$.
\end{abstract}

Keywords: Nanoparticles; Nano nickel; Nano-rod

\section{Introduction}

Cobalt borides are inorganic borides with general formula $\mathrm{Co}_{m} \mathrm{~B}_{\mathrm{n}}$. The most common cobalt borides are $\mathrm{CoB}$ and $\mathrm{Co}_{2} \mathrm{~B}$. Cobalt boride nanoparticles in the size range of 18 to $22 \mathrm{~nm}$ have been produced. The physical properties of cobalt borides are refractory materials, highly resistant to oxidation. It increases the lifespan of metal parts when used as coating, It imparts surface corrosion and wear resistant, It is used as catalyst for reduction [1] and fuel cell technologies, and they are applied in biomedical sciences for the design of drug delivery system. The cobalt borides exhibit super paramagnetic regime at room temperature, whereas the largest particles show ferromagnetic behavior [2].

Nano nickel boride $\mathrm{Ni}_{7} \mathrm{~B}_{3}$, is an example of metal-rich boride. Wodnieka et al. crystallized amorphous Nickel-boride alloys and observed a side product in the final yield [3]. A similar behavior was seen when thin films of $\mathrm{Ni}_{3} \mathrm{~B}$ were synthesized by chemical vapor deposition method [4] or during the crystallization of Nickel-Boron metallic glasses [5]. Machizaud et al. studied an amorphous alloy, $\mathrm{Ni}_{66} \mathrm{~B}_{34}$, and postulated that $\mathrm{Ni}_{7} \mathrm{~B}_{3}$ decomposes above $500^{\circ} \mathrm{C}$ to form $\mathrm{Ni}_{3} \mathrm{~B}$ and $\mathrm{Ni}_{2} \mathrm{~B}$ [6]. Lattice parameters are known from electron diffraction [3]. Katherine et al. described that $\mathrm{Ni}_{2} \mathrm{~B}_{3}$ is the first binary boride of a $3 \mathrm{~d}$ metal and proposed that a single-phase bulk synthesis of $\mathrm{Ni}_{7} \mathrm{~B}_{3}$ that crystallized with unknown disordered structure [7].

Zahida et al. have demonstrated that the metal-rich $\mathrm{Ni}_{7} \mathrm{~B}_{3}$ is paramagnetic. They also exhibit small ferromagnetic impurity. A very weak temperature independent paramagnetism was found for Nickel boride [8].

Due to special characters of transition metal borides including high hardness, high melting points, high-temperature strength, corrosion resistance, chemical stability, wear resistance and electrical properties, transition metal borides have a wide applications in different fields like medicine, high resistant furnaces and others [9-14].

Several synthetic procedures were applied to produce borides almost none of these studies proved the formation of single phase borides, rather a mixture of boride phases was formed [15,16]. In this paper two different procedures have been carried out in the synthetic process of Cobalt, Nickel and Copper borides, namely, solid states and wet reaction.

One of the elements which did not react with boron was copper. It was found to cause some wetting problems which made the addition of this metal rather useless. One of the elements which did not react with boron was copper. It was found to cause some wetting problems which made the addition of this metal rather useless. One of the elements which did not react with boron was copper. It was found to cause some wetting problems which made the addition of this metal rather useless.

\section{Experimentation/Empirical Analysis}

\section{Reagents}

Unless otherwise specified, reagent grade chemicals were employed. The precursor materials were Cobalt Oxide Black (CoO, BDH), and Nickel Oxide (NiO, BDH), Boron Powder (Amorphous) (B, Loba Chemie), Boron (III) Oxide ( $\mathrm{B}_{2} \mathrm{O}_{3}$, Alfa Aesar), Magnesium Powder (BDH), Cobalt (II) Chloride ( $\mathrm{CoCl}_{2}$, Fluka AG), Nickel (II) Chloride Hexahydrate Puriss $\left(\mathrm{NiCl}_{2} .6 \mathrm{H}_{2} \mathrm{O}\right.$, Riedel_de Haen), Cupper Chloride Dihydrate $\left(\mathrm{CuCl}_{2} \cdot 2 \mathrm{H}_{2} \mathrm{O}\right.$, Alfa Aesar). Cobalt Powder (Co, Alfa Aesar), Copper Powder ( $\mathrm{Cu}$, Alfa Aesar), Sodium Borohydride $\left(\mathrm{NaBH}_{4}\right.$, SigmaAldrich), Hydrochloric acid ( $\mathrm{HCl}$, Sigma-Aldrich, fuming >37\%).

The Powder X-ray diffraction (XRD) measurement was carried out with a Bruker D8 Advance diffractometer (CuKa $\lambda=1.54 \AA$; Ni filter; 40 $\mathrm{KV}, 40 \mathrm{~mA}$; Divergence slit: $1 \mathrm{~mm}$, LynxEye one-dimensional detector, Detector slit: $8 \mathrm{~mm}$ ). Scanning Electron Microscope and Transmission Electron Microscope (SEM and TEM) were performed by employing a microscope of model Titan 80-300 CT from FEI Company (Hillsboro, OR), which was equipped with a field emission gun (FEG) and a charged-Couple Devices $(C C D)$ camera of $4 \mathrm{k} \times 4 \mathrm{k}$ pixels. Furthermore, the analyses of all samples were performed by operating the microscope at $300 \mathrm{kV}$ accelerating voltage in order to take full advantage of the highest spatial resolution possible from this microscope. An aperture of 100 microns was also inserted into the back-focal plane (BPF) of

${ }^{*}$ Corresponding author: Al-Zain Omar Ali, Department of Chemistry, Faculty of Science, King Abdulaziz University, Jiddah, Saudi Arabia, Tel: 966555600872 ; E-mail: alzain2005@yahoo.com

Received: November 30, 2017; Accepted: December 15, 2017; Published: December 22, 2017

Citation: Ali AZO, Al-Masoudi, Soliyman R (2017) Nano-Metal Borides of Cobalt, Nickel and Copper. J Nanomed Nanotechnol 8: 477. doi: 10.4172/21577439.1000477

Copyright: ( 2017 Ali AZO, et al. This is an open-access article distributed under the terms of the Creative Commons Attribution License, which permits unrestricted use, distribution, and reproduction in any medium, provided the original author and source are credited. 
the objective lens, to improve the image contrast. The Magnetization measurement was carried out in an ever-cool Squid-Vibrating Sample Magnetometer (SVSM), from the manufacturer Quantum Design, USA.

\section{Synthesis}

\section{Solid phase}

\section{Preparation of metal borides using boron oxide and magnesium}

Cobalt boride: $2.2479 \mathrm{~g}$ of Cobalt Oxide (10 mmol), $0.6962 \mathrm{~g}$ Boron (III) Oxide $(10 \mathrm{mmol})$ and $0.4861 \mathrm{~g}$ Magnesium $(10 \mathrm{mmol})$, were mixed in a porcelain crucible. Mixture was placed in a muffle furnace. Heating was started at $600^{\circ} \mathrm{C}$ and temperature elevated subsequently up to $900^{\circ} \mathrm{C}$. XRD shows that the reaction product was $\mathrm{Co}_{3} \mathrm{O}_{4}$.

\section{$3 \mathrm{CoO}+\mathrm{B}_{2} \mathrm{O}_{3}+2 \mathrm{Mg} \stackrel{\Delta}{\longrightarrow} \mathrm{Co}_{3} \mathrm{O}_{4}+2 \mathrm{~B}+2 \mathrm{MgO}$}

Nickel boride: $1.4939 \mathrm{~g}$ of Nickel Oxide (20 mmol), $1.3924 \mathrm{~g}$ Boron (III) Oxide ( $20 \mathrm{mmol})$ and $1.4583 \mathrm{~g}$ Magnesium $(10 \mathrm{mmol})$, were mixed in a porcelain crucible and placed in a muffle furnace. Since the melting point of $\mathrm{Mg}$ is $650^{\circ} \mathrm{C}$, reaction was started at $600^{\circ} \mathrm{C}$ and temperature was elevated subsequently up to $900^{\circ} \mathrm{C}$. XRD shows that the reaction product is a nickel oxide.

$$
\mathrm{NiO}+\mathrm{B}_{2} \mathrm{O}_{3}+3 \mathrm{Mg} \stackrel{\Delta}{\longrightarrow} \mathrm{NiO}+2 \mathrm{~B}+3 \mathrm{MgO}
$$

\section{Preparation of metal borides using metal oxide and boron powder}

Cobalt boride: $7.4933 \mathrm{~g}$ of Cobalt Oxide $(100 \mathrm{mmol})$ and $2.1622 \mathrm{~g}$ of Boron Powder $(100 \mathrm{mmol})$, were mixed in a porcelain crucible and placed in a muffle furnace. Temperature was set up at 400 and elevated to $500^{\circ} \mathrm{C}$ for six hours. After cooling to the room temperature the black precipitate was leached with concentrated hydrochloric acid (conc. $\mathrm{HCl}$ ) for one hour under magnetic stirring. Product was filtered and washed with distilled water three times and then dried in the vacuum oven at $150^{\circ} \mathrm{C}$ for 3 hours. Yield was $\mathrm{CoB}_{2} \mathrm{O}_{4}$

$$
\mathrm{CoO}+2 \mathrm{~B} \underset{400-500^{\circ} \mathrm{C}}{\stackrel{\mathrm{x}}{\longrightarrow}} \mathrm{CoB}_{2} \mathrm{O}_{4}
$$

Nickel boride: $7.4693 \mathrm{~g}$ of Nickel Oxide $(10 \mathrm{mmol})$ and $0.3243 \mathrm{~g}$ Amorphous Boron Powder $(10 \mathrm{mmol})$, were mixed in a porcelain crucible and placed in a muffle furnace at $500-600^{\circ} \mathrm{C}$ for four hours. After cooling to the room temperature in a muffle furnace, the black precipitate was leached in concentrated hydrochloric acid (conc. $\mathrm{HCl}$ ) for one hour under magnetic stirring. Product was filtered and washed with distilled water three times and then dried in the vacuum oven at $150^{\circ} \mathrm{C}$ for 3 hours. Yield was $\mathrm{NiO}$.

$$
\mathrm{NiO}+2 \mathrm{~B} \underset{500-600^{\circ} \mathrm{C}}{\stackrel{x\left[\mathrm{O}_{2}\right]}{\longrightarrow}} \mathrm{NiO}+\mathrm{B}_{2} \mathrm{O}_{3}
$$

\section{Preparation of metal borides using metal chlorides and boron}

Cobalt boride: $3.8952 \mathrm{~g}$ of Cobalt Chloride Anhydrous (10 $\mathrm{mmol}$ ) and $0.4324 \mathrm{~g}$ Boron Powder $(10 \mathrm{mmol})$, were mixed in a porcelain crucible and placed in a muffle furnace. Temperature was ranged between 400 and $700^{\circ} \mathrm{C}$ for six hours. After cooling to room temperature in a muffle furnace, the black precipitate was leached in 1 $\mathrm{N} \mathrm{HCl}$ for three hour under magnetic stirring. Product was filtered and washed with distilled water three times and then dried in the vacuum oven at $150^{\circ} \mathrm{C}$ for 3 hours. The yield is $54.89 \%$.

$$
3 \mathrm{CoCl}_{2}+4 \mathrm{~B} \underset{400-700^{\circ} \mathrm{C}}{\stackrel{\Delta}{\longrightarrow}} \mathrm{Co}_{2} \mathrm{~B}+\mathrm{CoB}+2 \mathrm{BCl}_{3}
$$

Nickel boride: $3.8879 \mathrm{~g}$ of Nickel Oxide $(10 \mathrm{mmol})$ and 0.21622 g Amorphous Boron Powder $(50 \mathrm{mmol})$, were mixed in a porcelain crucible and placed in a muffle furnace at $500-600^{\circ} \mathrm{C}$ for four hours.
After cooling to the room temperature in a muffle furnace, the black precipitate was leached in concentrated hydrochloric acid (conc. $\mathrm{HCl}$ ) for one hour under magnetic stirring. Product was filtered, washed with distilled water three times and then dried in the vacuum oven at $150^{\circ} \mathrm{C}$ for 3 hours. Yield was $\mathrm{NiO}$.

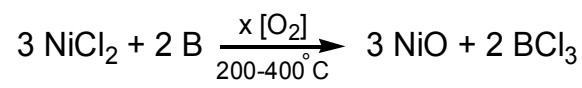

Preparation of metal borides using metal chlorides with boron, sodium and aluminum chloride

Cobalt boride: $1.2984 \mathrm{~g}$ of Cobalt Chloride Anhydrous (10 mmol), $0.2162 \mathrm{~g}$ Boron Powder ( $10 \mathrm{mmol}), 0.4598 \mathrm{~g}$ Sodium $(10 \mathrm{mmol})$ and 5 $\mathrm{g}$ of Anhydrous Aluminum (III) Chloride were mixed in a porcelain crucible and placed in a muffle furnace. Temperature gradually raised starting $300^{\circ} \mathrm{C}$ for two hours then $600^{\circ} \mathrm{C}$ for four hours and finally $1000^{\circ} \mathrm{C}$ for 12 hours. After cooling to room temperature the mixture was leached with $1 \mathrm{~N} \mathrm{HCl}$ at $100^{\circ} \mathrm{C}$ for three hour under magnetic stirring. Solution was filtered and washed with distilled water, $1 \mathrm{~N}$ $\mathrm{NaOH}$ and absolute ethanol and dried in a vacuum oven at $150^{\circ} \mathrm{C}$ for 3 h. Yield was $\mathrm{CoB}_{2} \mathrm{O}_{4}$.

$$
\mathrm{CoCl}_{2}+2 \mathrm{~B}+2 \mathrm{Na} \underset{300-1000^{\circ} \mathrm{C}}{\stackrel{\mathrm{x}\left[\mathrm{O}_{2}\right]}{\longrightarrow}} \mathrm{CoB}_{2} \mathrm{O}_{4}+2 \mathrm{NaCl}
$$

\section{Preparation of metal borides using metal powder and boron}

Cobalt boride: $5.8933 \mathrm{~g}$ of Cobalt $(100 \mathrm{mmol})$ and $1.0811 \mathrm{~g}$ Amorphous Boron Powder (100 mmol), were mixed in a porcelain crucible and placed in a muffle furnace at $700-900^{\circ} \mathrm{C}$ for five hours under inert atmosphere. After cooling to the room temperature in a muffle furnace, the black precipitate was leached in concentrated hydrochloric acid (conc. $\mathrm{HCl}$ ) for 24 hours under magnetic stirring. Product was filtered and washed with distilled water three times and then dried in the vacuum oven at $150^{\circ} \mathrm{C}$ for 3 hours. Yield was $46 \%$.

$$
\mathrm{Co}+\mathrm{B} \underset{700-900^{\circ} \mathrm{C}}{\stackrel{\Delta}{\longrightarrow}} \mathrm{CoB} \quad 1: 1
$$

$5.8933 \mathrm{~g}$ of Cobalt $(100 \mathrm{mmol})$ and $2.1622 \mathrm{~g}$ Boron Powder (200 $\mathrm{mmol}$ ), were mixed in a porcelain crucible and placed in a muffle furnace. Temperature was ranged between 700 and $900^{\circ} \mathrm{C}$ for five hours under inert atmosphere (argon atmosphere). After cooling to the room temperature, the black precipitate was leached in concentrated hydrochloric acid (conc. $\mathrm{HCl}$ ) for 24 hours under magnetic stirring. Product was filtered and washed with distilled water three times and then dried in the vacuum oven at $150^{\circ} \mathrm{C}$ for 3 hours. Yield was $53 \%$.

$$
\mathrm{Co}+2 \mathrm{~B} \underset{700-900^{\circ} \mathrm{C}}{\stackrel{\Delta}{\longrightarrow}} \mathrm{CoB}_{2} \quad 1: 2
$$

$5.8933 \mathrm{~g}$ of Cobalt $(100 \mathrm{mmol})$ and $3.2433 \mathrm{~g}$ Amorphous Boron Powder $(300 \mathrm{mmol})$, were mixed in a porcelain crucible and placed in a muffle furnace at $700-900^{\circ} \mathrm{C}$ for five hours under inert atmosphere. After cooling to the room temperature in a muffle furnace, the black precipitate was leached in concentrated hydrochloric acid (conc. $\mathrm{HCl}$ ) for 24 hours under magnetic stirring. Product was filtered and washed with distilled water three times and then dried in the vacuum oven at $150^{\circ} \mathrm{C}$ for 3 hours. Yield was $61 \%$.

$$
\mathrm{Co}+\mathrm{B} \underset{700-900^{\circ} \mathrm{C}}{\stackrel{\Delta}{\longrightarrow}} \mathrm{CoB} \quad 1: 3
$$

Copper boride: $6.3546 \mathrm{~g}$ of Copper $(100 \mathrm{mmol})$ and $1.0811 \mathrm{~g}$ Amorphous Boron Powder $(200 \mathrm{mmol})$, were mixed in a porcelain crucible and placed in a muffle furnace at $700-900^{\circ} \mathrm{C}$ for five under inert atmosphere. After cooling to the room temperature in a muffle furnace, the precipitate was leached in concentrated hydrochloric acid (conc. $\mathrm{HCl}$ ) for 24 hours under magnetic stirring. Product was filtered and 
washed with distilled water three times and then dried in the vacuum oven at $150^{\circ} \mathrm{C}$ for 3 hours. Yield was $30 \%$.

$$
\mathrm{Cu}+\mathrm{B} \underset{700-900^{\circ} \mathrm{C}}{\stackrel{\Delta}{\longrightarrow}} \mathrm{CuB} \quad 1: 1
$$

$6.3546 \mathrm{~g}$ of Copper $(100 \mathrm{mmol})$ and $2.1622 \mathrm{~g}$ Amorphous Boron Powder $(200 \mathrm{mmol})$, were mixed in a porcelain crucible and placed in a muffle furnace at $700-900^{\circ} \mathrm{C}$ for five hours under inert atmosphere. After cooling to the room temperature in a muffle furnace, the precipitate was leached in concentrated hydrochloric acid (conc. $\mathrm{HCl}$ ) for 24 hours under magnetic stirring. Product was filtered and washed with distilled water three times and then dried in the vacuum oven at $150^{\circ} \mathrm{C}$ for 3 hours. Yield was $47 \%$.

$$
\mathrm{Cu}+2 \mathrm{~B} \underset{700-900^{\circ} \mathrm{C}}{\stackrel{\Delta}{\longrightarrow}} \mathrm{CuB}_{2} \quad 1: 2
$$

$6.3546 \mathrm{~g}$ of Copper $(100 \mathrm{mmol})$ and $3.2433 \mathrm{~g}$ Amorphous Boron Powder (300 $\mathrm{mmol})$, were mixed in a porcelain crucible and placed in a muffle furnace at $700-900^{\circ} \mathrm{C}$ for five hours under inert atmosphere. After cooling to the room temperature in a muffle furnace, the precipitate was leached in concentrated hydrochloric acid (conc. $\mathrm{HCl}$ ) for 24 hours under magnetic stirring. Product was filtered and washed with distilled water three times and then dried in the vacuum oven at $150^{\circ} \mathrm{C}$ for 3 hours. Yield was $\mathrm{Cu}\left(\mathrm{BO}_{2}\right)_{2}$.

$$
\mathrm{Cu}+2 \mathrm{~B} \underset{700-900^{\circ} \mathrm{C}}{\mathrm{x}\left[\mathrm{O}_{2}\right]} \mathrm{Cu}\left(\mathrm{BO}_{2}\right)_{2} \quad 1: 3
$$

\section{Liquid phase}

Preparation of metal borides using metal chlorides and sodium borohydride

Cobalt boride: $1.2984 \mathrm{~g}$ of Anhydrous Cobalt Chloride (10 mmol) was dissolved in $100 \mathrm{ml}$ distilled water, stirred on a magnetic stirrer. $0.7566 \mathrm{~g}(10 \mathrm{mmol})$ of sodium borohydride was dissolved in $50 \mathrm{ml}$ distilled water and dropwise added from separator funnel. Mixture was left stirring for 30 minutes at room temperature. The precipitate was filtered and carefully washed with dilute hydrochloric acid then with distilled water. $\mathrm{CoB}_{2} \mathrm{O}_{4}$ Precipitate was dried in the oven (open air) at $400^{\circ} \mathrm{C}$ for five hours. Yield was $\mathrm{CoB}_{2} \mathrm{O}_{4}$.

$$
\mathrm{CoCl}_{2}+2 \mathrm{NaBH}_{4}+4 \mathrm{H}_{2} \mathrm{O} \longrightarrow \mathrm{CoB}_{2} \mathrm{O}_{4}+2 \mathrm{NaCl}+4 \mathrm{H}_{2}
$$

Nickel boride: $3.8032 \mathrm{~g}$ of Nickel Chloride Hexahydrate (2 mmol) was dissolved in $100 \mathrm{ml}$ distilled water, stirred on a magnetic stirrer. $1.2106 \mathrm{~g}$ ( $2 \mathrm{mmol})$ of sodium borohydride was dissolved in $50 \mathrm{ml}$ distilled water and dropwise added from separator funnel and left stirring for 30 minutes at room temperature. The precipitate was filtered and carefully washed with dilute hydrochloric acid then with distilled water. $\mathrm{Ni}_{4} \mathrm{~B}_{3}$ Precipitate was dried in the oven (open air) at $400^{\circ} \mathrm{C}$ for five hours. Yield was $75 \%$.

$8 \mathrm{NiCl}_{2}+16 \mathrm{NaBH}_{4}+30 \mathrm{H}_{2} \mathrm{O} \longrightarrow 2 \mathrm{Ni}_{4} \mathrm{~B}_{3}+16 \mathrm{NaCl}+47 \mathrm{H}_{2}+10 \mathrm{~B}(\mathrm{OH})_{3}$

Copper boride: $2.0458 \mathrm{~g}$ of Copper Chloride Dihydrate $(1 \mathrm{mmol})$ was dissolved in $100 \mathrm{ml}$ distilled water, stirred on a magnetic stirrer and $1.8158 \mathrm{~g} \mathrm{(} 2 \mathrm{mmol})$ of sodium borohydride dissolved in $50 \mathrm{ml}$ distilled water and dropwise added from separator funnel and left stirring for 30 minutes. The precipitate was filtered and carefully washed with dilute hydrochloric acid then with distilled water. $\mathrm{CuB}_{24}$ Precipitate was dried in the oven (open air) at $400^{\circ} \mathrm{C}$ for five hours. Yield was $58 \%$.

$12 \mathrm{CuCl}_{2}+24 \mathrm{NaBH}_{4}+11 \mathrm{H}_{2} \mathrm{O} \longrightarrow \mathrm{CuB}_{24}+11 \mathrm{CuO}+24 \mathrm{NaCl}+59 \mathrm{H}_{2}$

\section{Results and Discussion}

Two different preparation methods, solid phase (five different ways) and liquid phase (one way), were attempted to reach the most proper way to produce $\mathrm{Co}, \mathrm{Ni}$ and $\mathrm{Cu}$ metal-borides.

\section{Solid phase}

Mixing stoichiometric amounts of $\mathrm{CoO}, \mathrm{B}_{2} \mathrm{O}_{3}$ and $\mathrm{Mg}$, either in open air or under a blanket of argon, yielded $\mathrm{Co}_{3} \mathrm{O}_{4}$. Direct reaction of cobalt metal oxide, $\mathrm{CoO}$, with elemental boron mixed in a porcelain crucible and placed in a muffle furnace for several hours under argon atmosphere yielded $\mathrm{CoB}_{2} \mathrm{O}_{4}$ (Figure 1a).

Reaction of cobalt chloride, $\mathrm{CoCl}_{2}$, with elemental boron mixed in a porcelain crucible and placed in a muffle furnace for six hours under argon atmosphere yielded a mixture of $\mathrm{CoB}$ and $\mathrm{Co}_{2} \mathrm{~B}$ (Figure $1 \mathrm{~b}$ ).

Reaction of a mixture of cobalt chloride, $\mathrm{CoCl}_{2}$, elemental boron and sodium metal in a muffle furnace at variant temperature and time $\left(300,600\right.$ and $1000^{\circ} \mathrm{C}$ for 12 hours) under argon atmosphere yielded $\mathrm{CoB}_{2} \mathrm{O}_{4}$ (Figure 1c). Direct reaction of cobalt metal and elemental boron tried in three different proportions (1:1, 1:2 and 1:3). Mixture was placed in a porcelain crucible in muffle furnace at $900^{\circ} \mathrm{C}$ for five hours under argon atmosphere. 1:3 Proportions was the best among all where produced $\mathrm{CoB}$ according to XRD graph (Figure 1d). SEM image shows an irregular texture of mixed crystals sizes (Figure 1e). Magnetic hysteresis (Figure 1f) shows that $\mathrm{CoB}$ possess superparamagnetism $[17,18]$. Magnesiothermic Reduction of $\mathrm{NiO}, \mathrm{B}_{2} \mathrm{O}_{3}$ and $\mathrm{Mg}$, either in

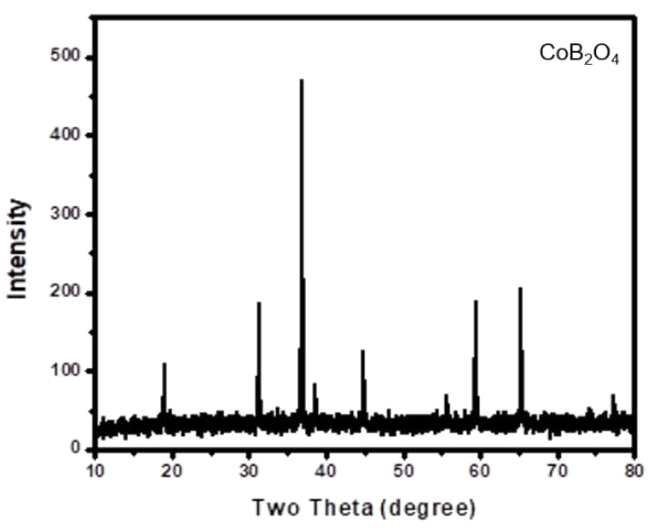

Figure 1a: XRD spectra of $\mathrm{CoB}_{2} \mathrm{O}_{4}$ produced by direct reaction of $\mathrm{CoO}$ and $\mathrm{B}$.

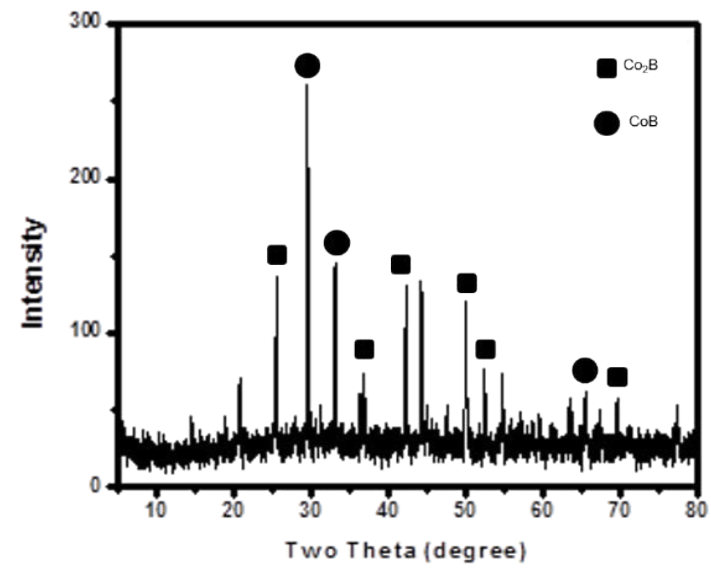

Figure 1b: XRD spectra of $\mathrm{CoB}$ and $\mathrm{Co}_{2} \mathrm{~B}$ produced by direct reaction of $\mathrm{CoCl}_{2}$ and $\mathrm{B}$. 


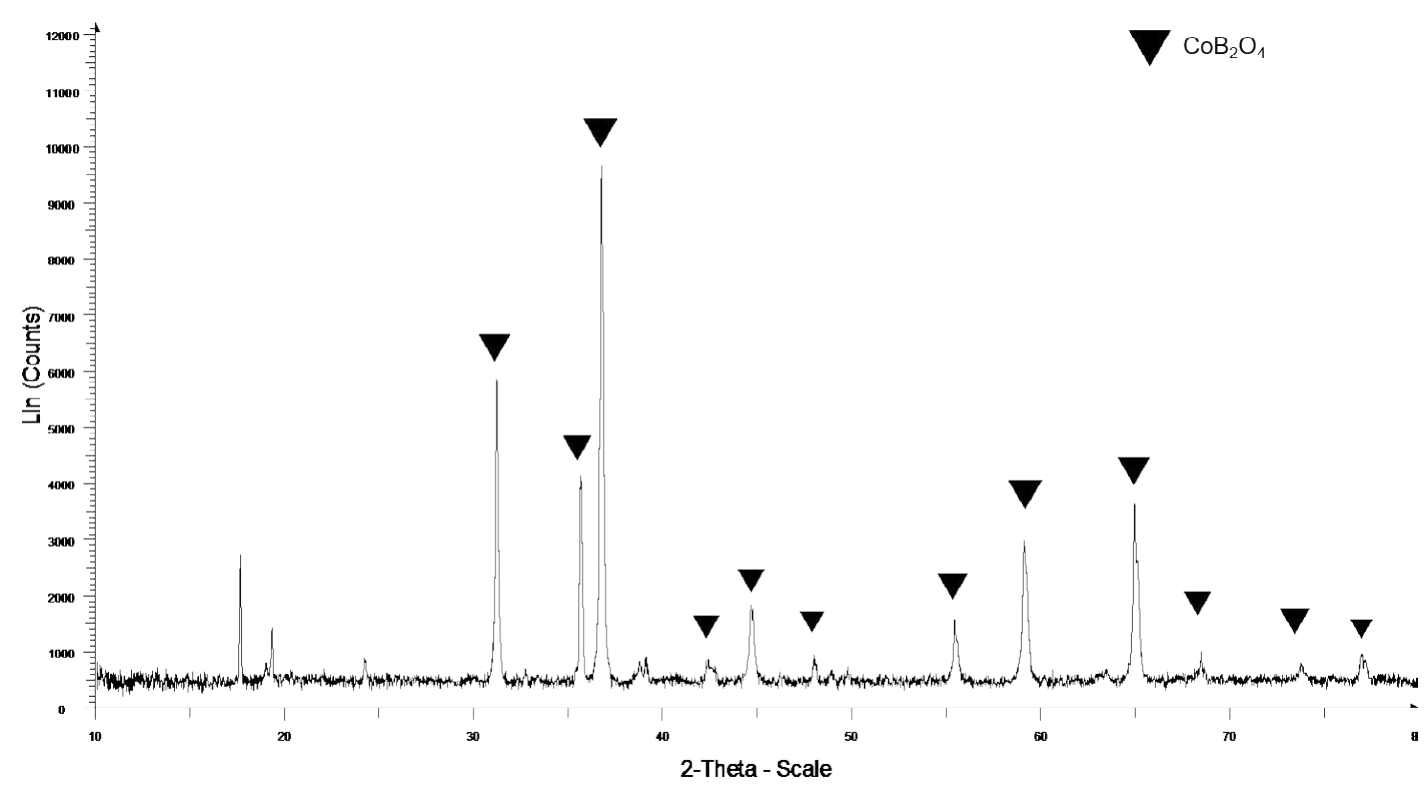

Figure 1c: XRD spectra of $\mathrm{CoB}_{2} \mathrm{O}_{4}$ produced by direct reaction of $\mathrm{CoCl}_{2}, \mathrm{~B}$ and $\mathrm{Na}$.

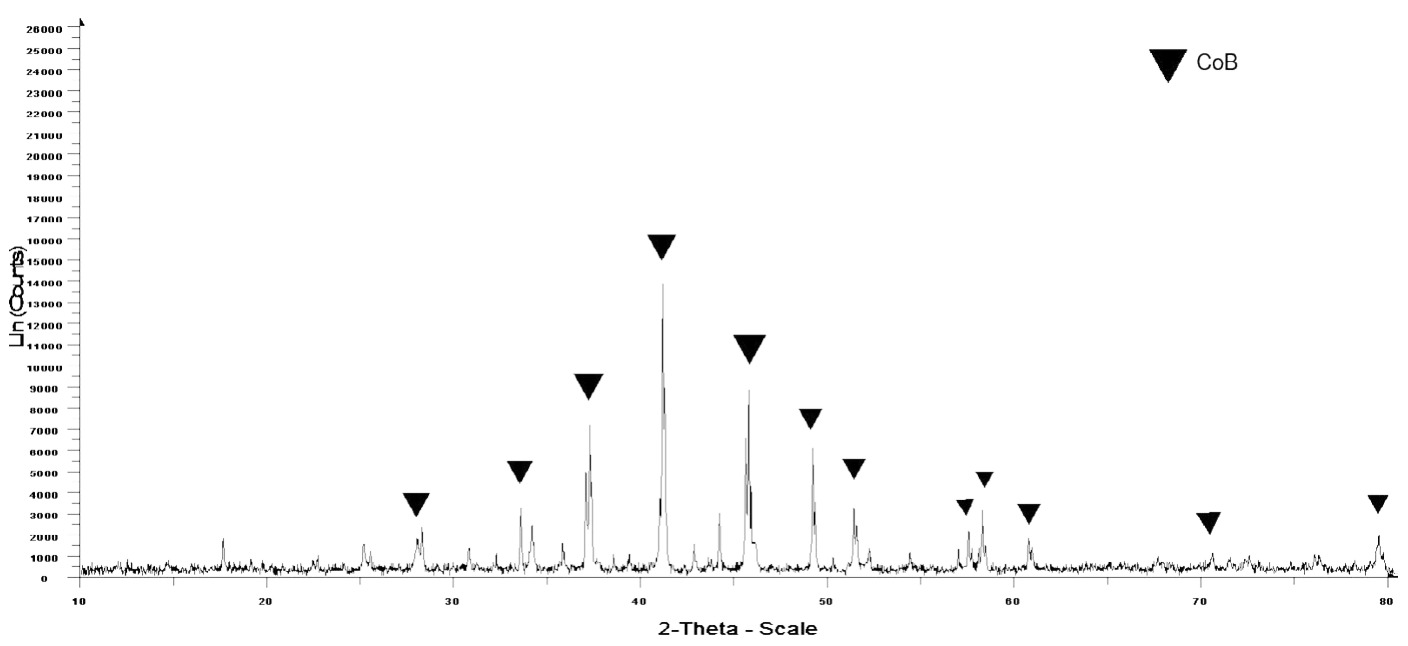

Figure 1d: XRD spectra of black crystals of $\mathrm{CoB}$ produced by direct reaction of $\mathrm{Co}$ and $\mathrm{B}$.
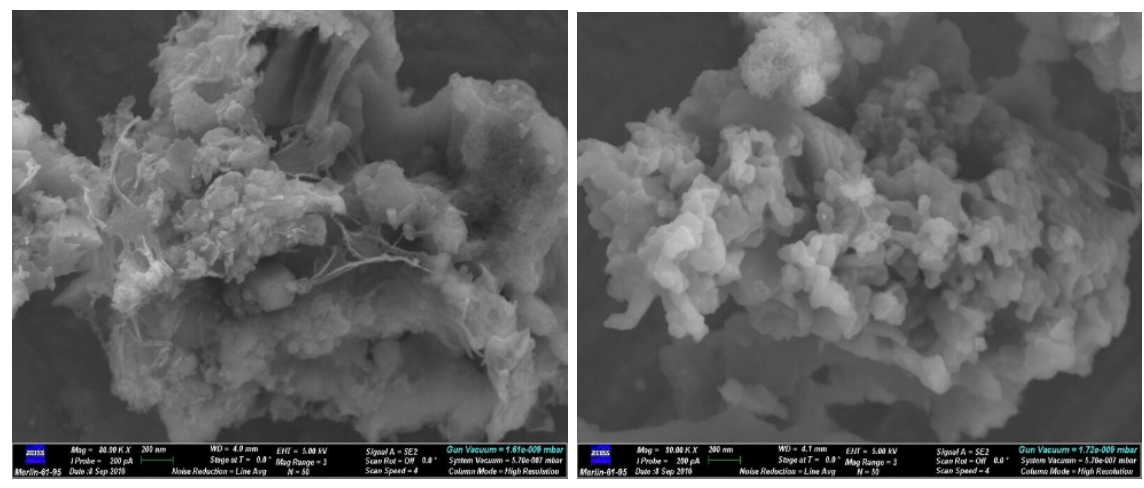

Figure 1e: SEM image of black crystals of CoB. 


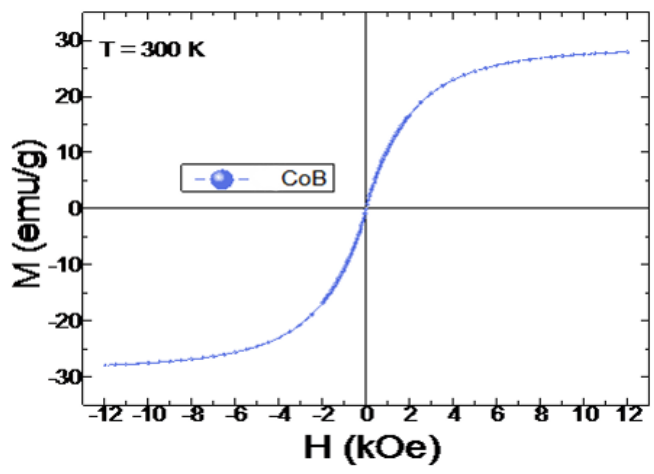

Figure 1f: Magnetic hysteresis of $\mathrm{CoB}$

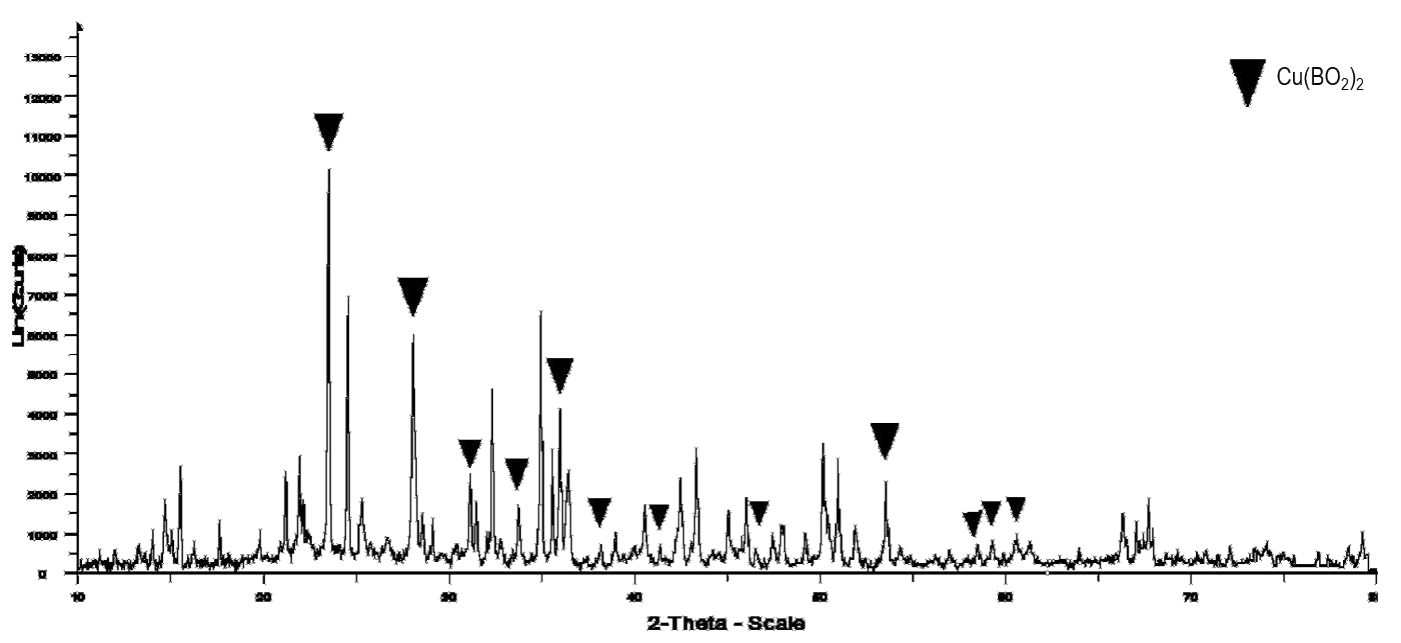

Figure 2a: XRD spectra of $\mathrm{Cu}\left(\mathrm{BO}_{2}\right)_{2}$ produced by direct reaction of $\mathrm{Cu}$ and $\mathrm{B}$.
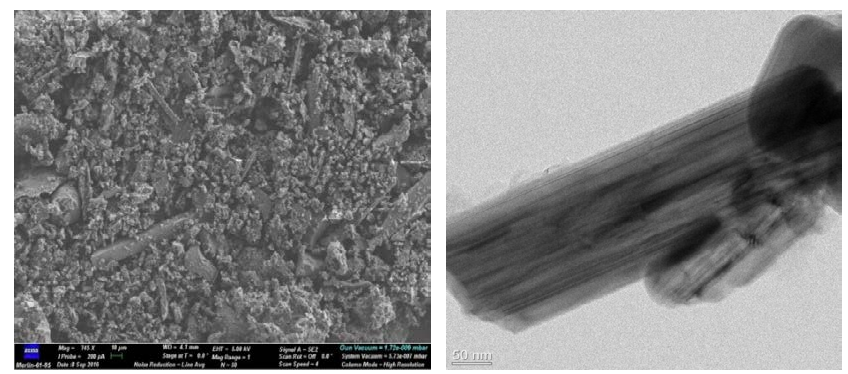

Figure 2b: SEM image of $\mathrm{Cu}\left(\mathrm{BO}_{2}\right)_{2}$

open air or under a blanket of argon, yielded only $\mathrm{NiO}$. Also a direction reaction of nickel oxide, $\mathrm{NiO}$, and chloride, $\mathrm{NiCl}_{2}$, with elemental boron mixed in a porcelain crucible and placed in a muffle furnace for several hours under argon atmosphere yielded Nickel oxides. Direction reaction of cupper metal with elemental boron tried in three proportions 1:1, 1:2 and 1:3. Proportion of 1:3 was the best among all where produced $\mathrm{Cu}\left(\mathrm{BO}_{2}\right)_{2}$ according to XRD graph (Figure 2a). SEM image (Figure 2b) shows an irregular texture of mixed crystals which is in agreement with of the XRD. Figure $2 c$ shows a low profile superparamagnetic curve which might indicates a nanocrystals and nanorods.

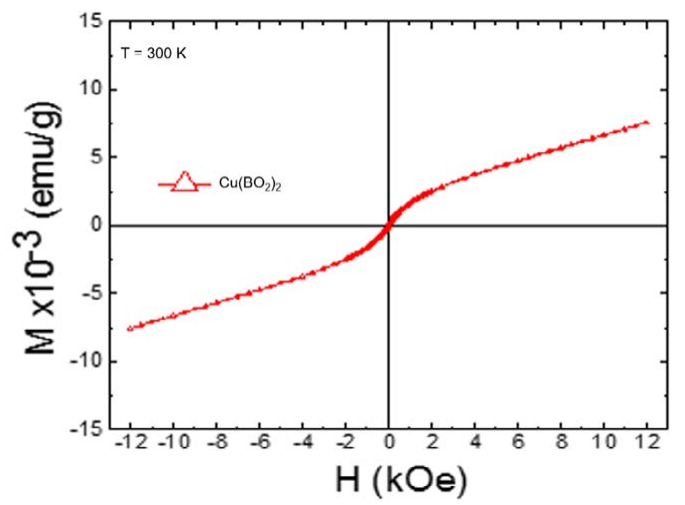

Figure 2c: Magnetic hysteresis of $\mathrm{Cu}\left(\mathrm{BO}_{2}\right)_{2}$.

\section{Liquid phase}

Addition of sodium borohydride, $\mathrm{NaBH}_{4}$ to cobalt (II) Chloride, $\mathrm{CoCl}_{2}$, solution (1:2 ratio) produced $\mathrm{CoB}_{2} \mathrm{O}_{4}$ as it could be seen in the XRD pattern (Figure 3a). SEM image (Figure $3 \mathrm{~b}$ ) shows a texture of crystals. TEM image (Figure 3c) clearly indicates nanocrystals and nanorods. Figure $3 \mathrm{~d}$ reflects regular paramagnetic properties of cobalt compound. Reaction of nickel (II) Chloride, $\mathrm{NiCl}_{2}$, with sodium borohydride, $\mathrm{NaBH}_{4}$, in solution (1:2 ratio) produced $\mathrm{Ni}_{4} \mathrm{~B}_{3}$ as XRD 


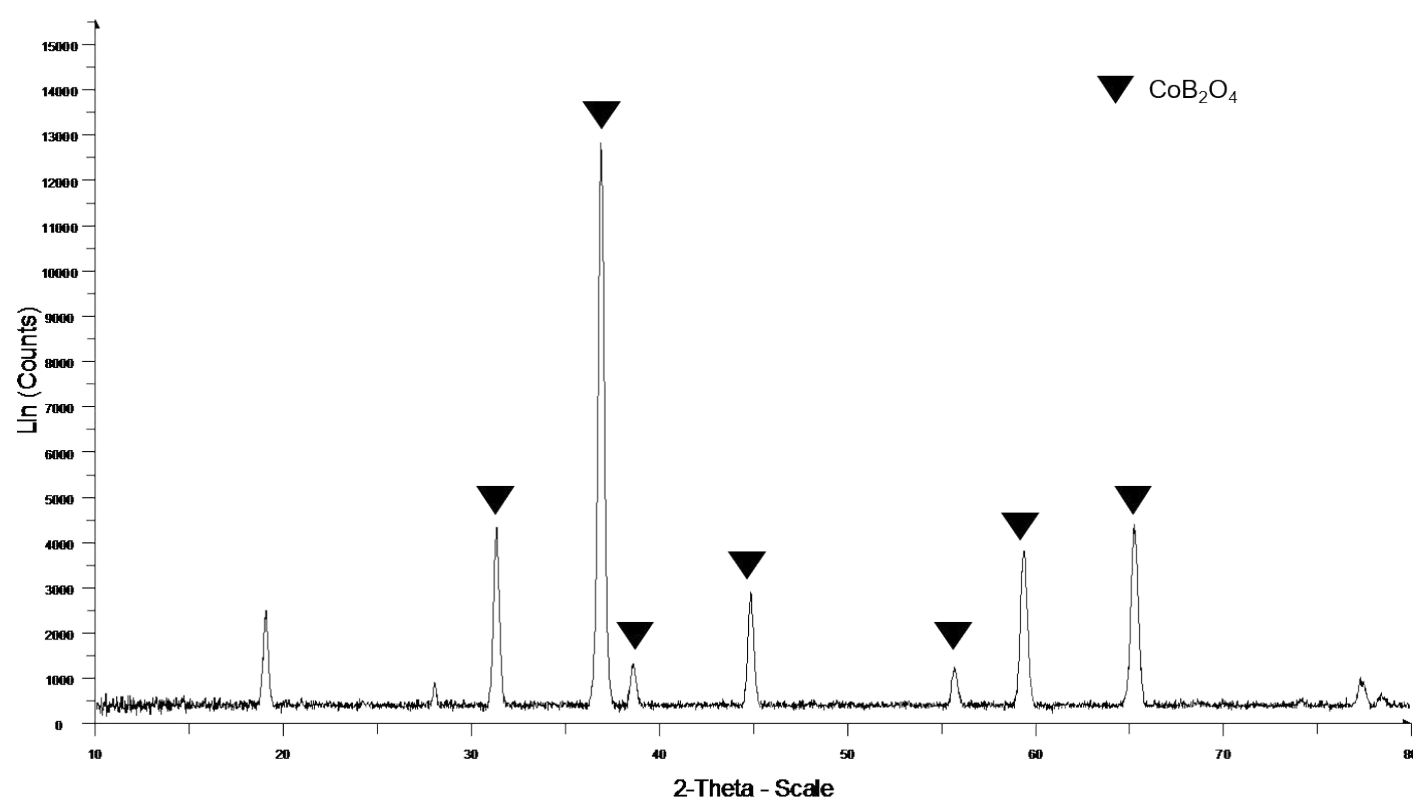

Figure 3a: XRD pattern of $\mathrm{CoB}_{2} \mathrm{O}_{4}$ yielded by reaction of $\mathrm{CoCl}_{2}$ with $\mathrm{NaBH}_{4}$.

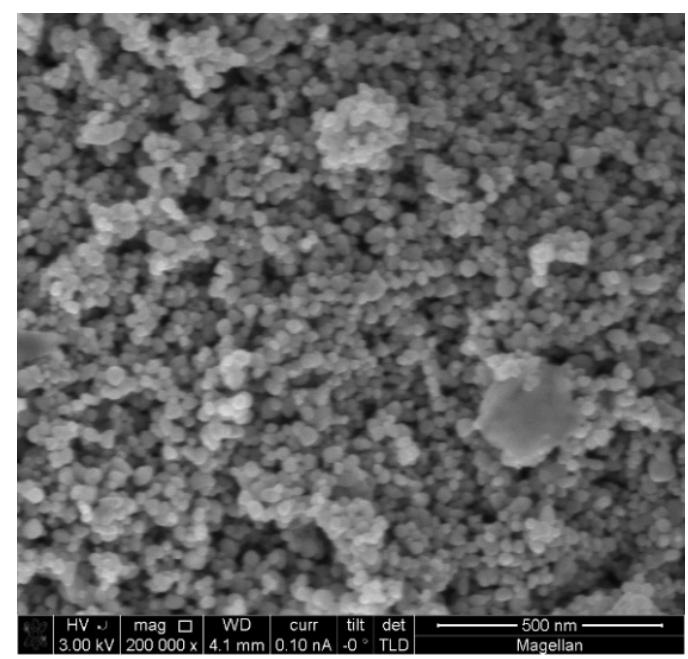

Figure 3b: SEM image of $\mathrm{CoB}_{2} \mathrm{O}_{4}$

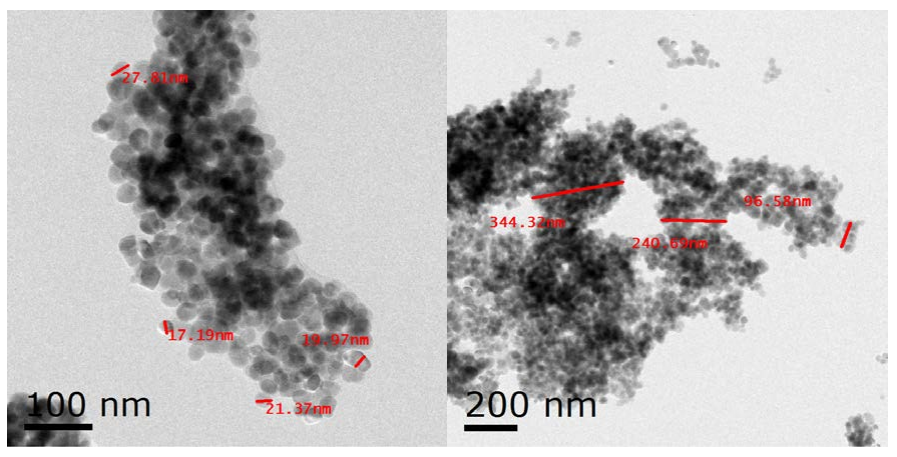

Figure 3c: TEM image of $\mathrm{CoB}_{2} \mathrm{O}_{4}$ 
pattern indicated (Figure 4a). TEM image (Figure 4b) clearly indicates nanocrystals and nanorods. Figure $4 \mathrm{c}$ shows superparamagnetic curve which in support of nanocrystals and nanorods. Copper (II) Chloride, $\mathrm{CuCl}_{2}$, reacted with sodium borohydride, $\mathrm{NaBH}_{4}$, in solution (1:2 ratio) to produce a mixture of $\mathrm{CuB}_{24}$ and $\mathrm{CuO}$ as the XRD pattern shows
(Figure 5a). SEM image (Figure 5b) shows the crystal texture of the product. TEM image (Figure 5c) clearly indicates nanocrystals and nanorods which is reflected on the magnetism of the product. Figure $5 \mathrm{~d}$ shows a low profile superparamagnetic curve which might indicates a nanocrystals and nanorods.x

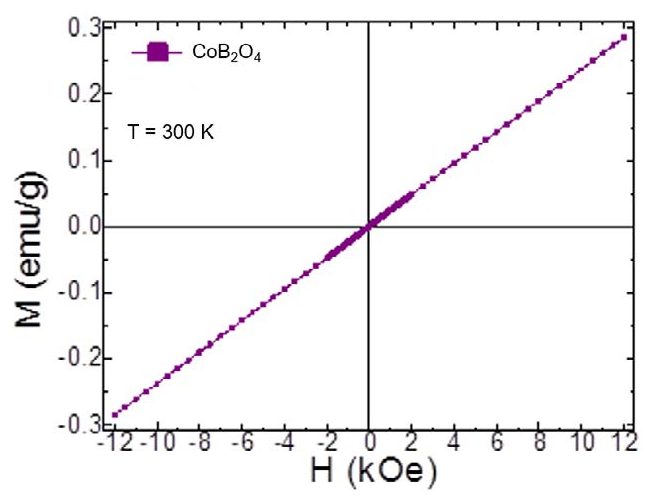

Figure 3d: Magnetic hysteresis of $\mathrm{CoB}_{2} \mathrm{O}_{4}$

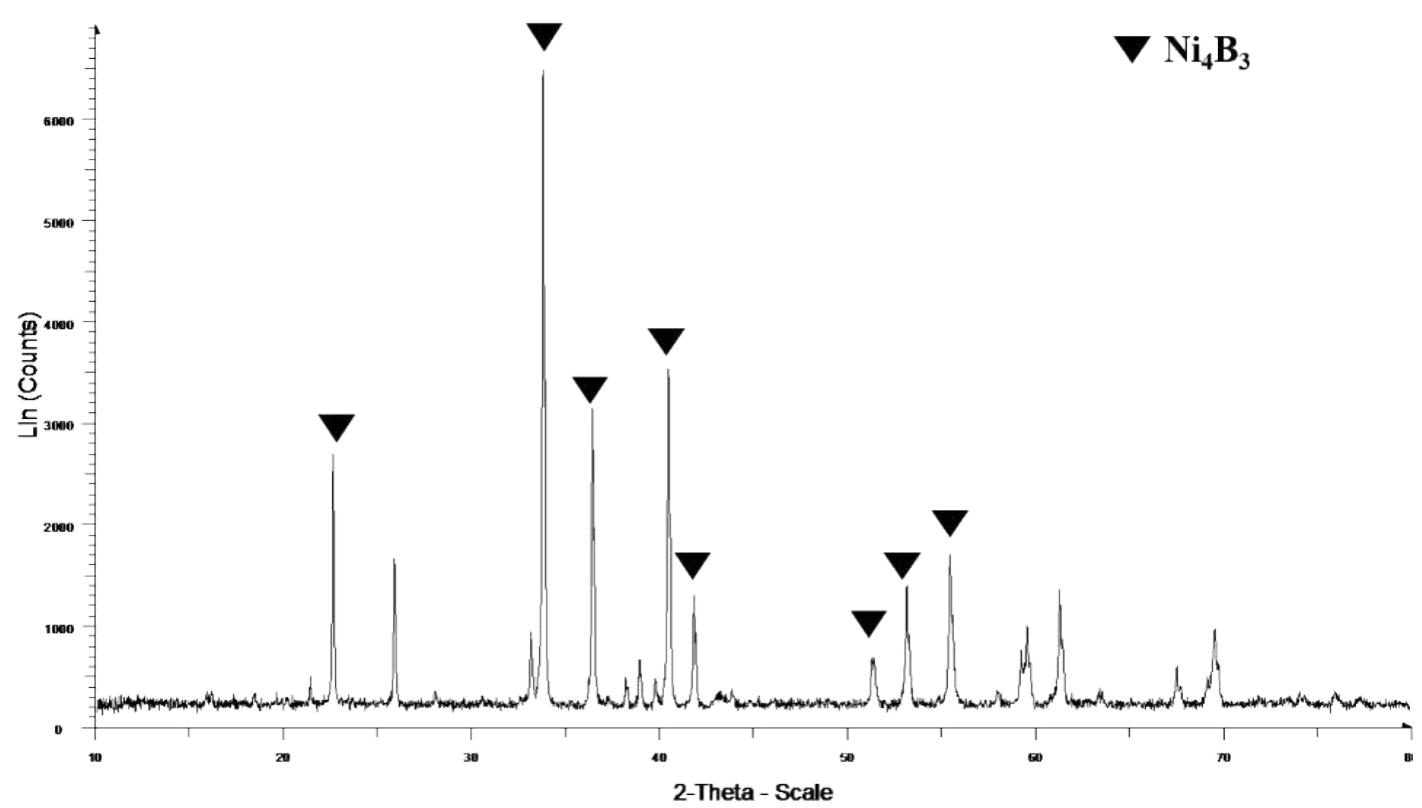

Figure 4a: XRD spectra of $\mathrm{Ni}_{4} \mathrm{~B}_{3}$ produced by direct reaction of $\mathrm{NiCl}_{2}$ with $\mathrm{NaBH}_{4}$.

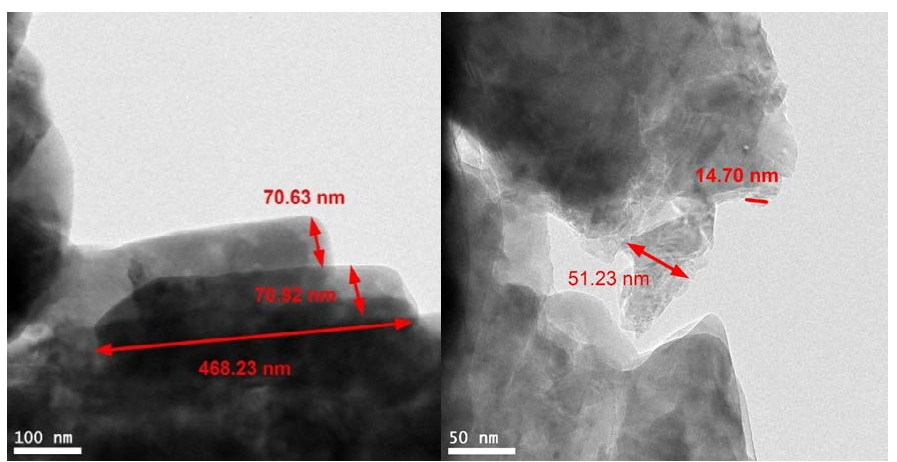

Figure $4 \mathbf{b}$ : TEM image of nanocrystals and nanorods of $\mathrm{Ni}_{4} \mathrm{~B}_{3}$. 


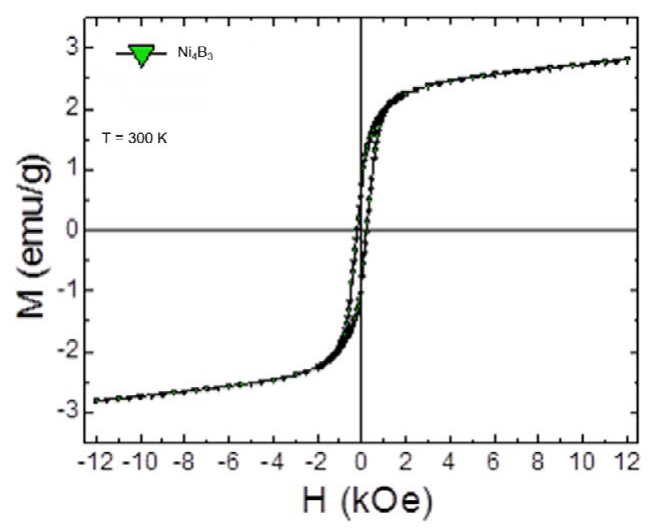

Figure 4c: Magnetic hysteresis superparamagnetism of $\mathrm{Ni}_{4} \mathrm{~B}_{3}$

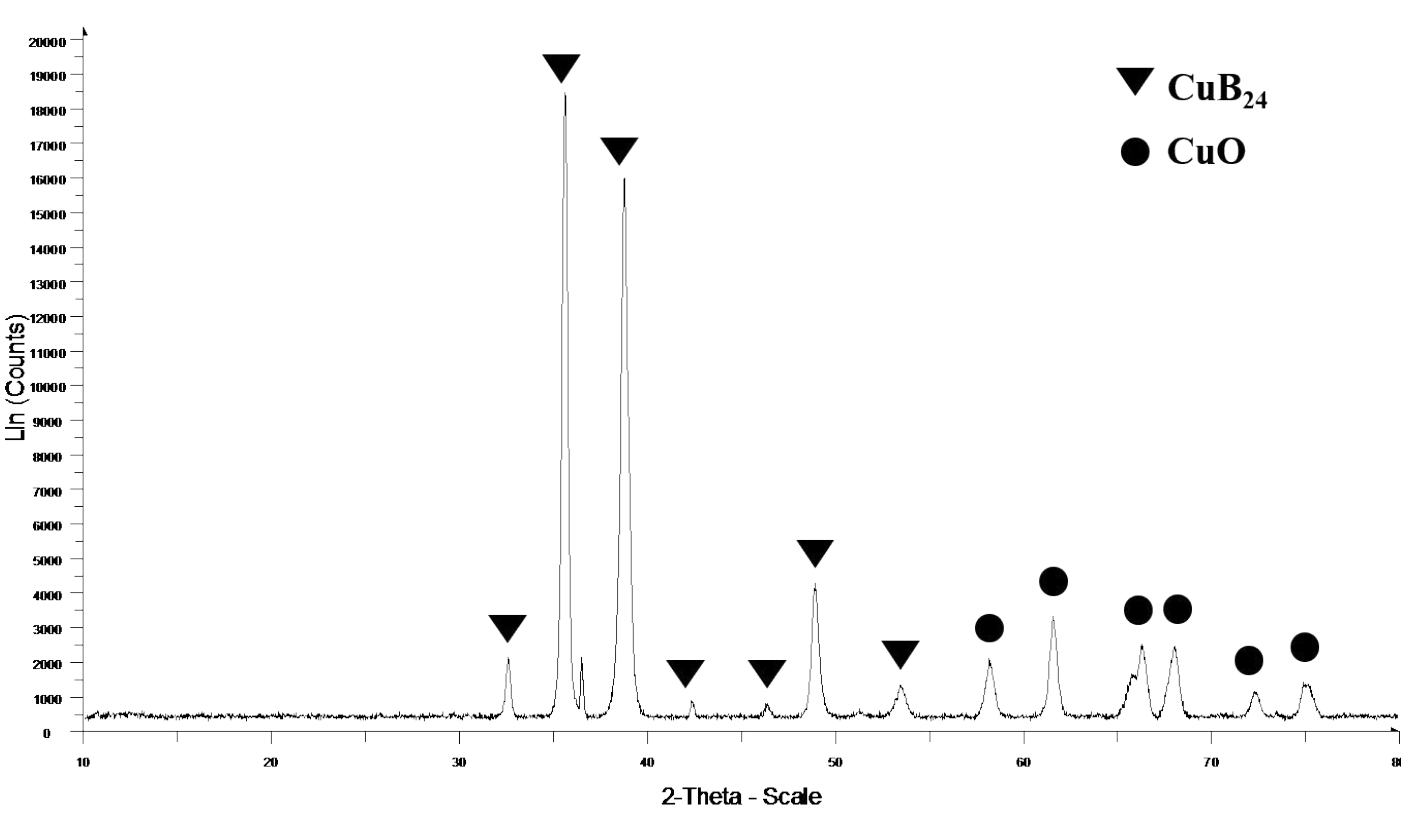

Figure 5a: XRD spectra of $\mathrm{CuB}_{24}$ and $\mathrm{CuO}$ by direct reaction of $\mathrm{CuCl}_{2}$ with $\mathrm{NaBH}_{4}$.

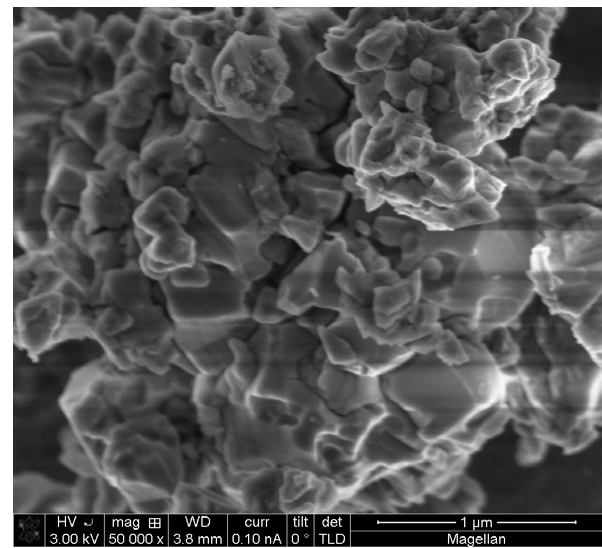

Figure 5b: SEM image of nanocrystals and nanorods of $\mathrm{CuB}_{24}$ and $\mathrm{CuO}$. 
Citation: Ali AZO, Al-Masoudi, Soliyman R (2017) Nano-Metal Borides of Cobalt, Nickel and Copper. J Nanomed Nanotechnol 8: 477. doi: 10.4172/2157-7439.1000477

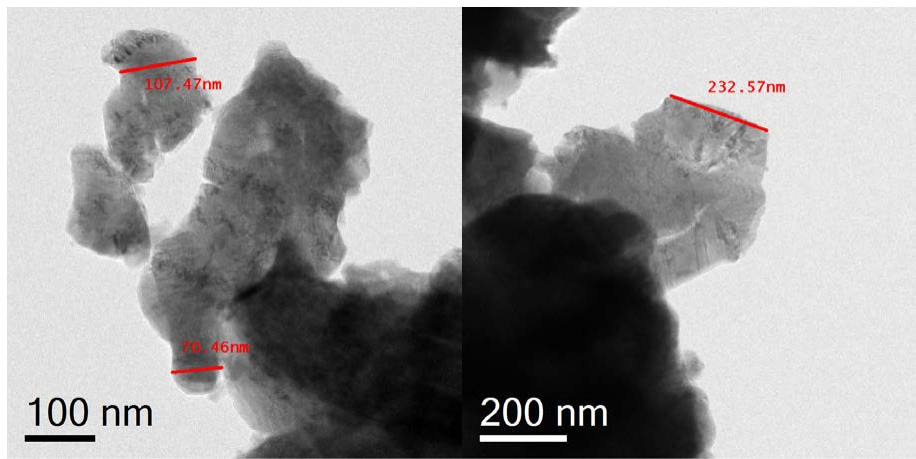

Figure 5c: TEM image of nanocrystals and nanorods of $\mathrm{CuB}_{24}$ and $\mathrm{CuO}$.

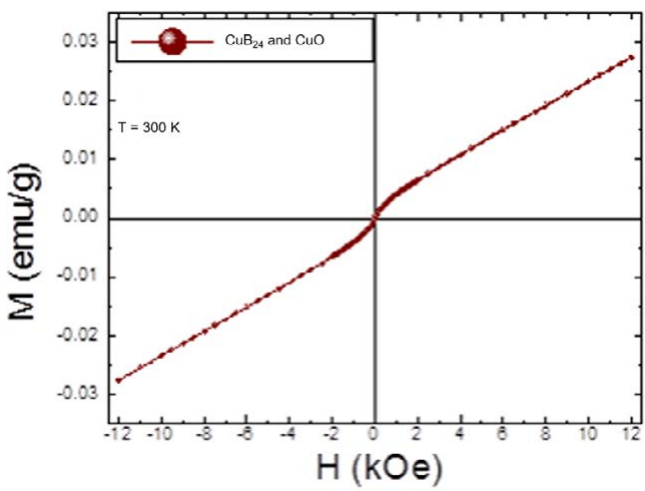

Figure 5d: Magnetic hysteresis of $\mathrm{CuB}_{24}$ and $\mathrm{CuO}$

\section{Conclusion}

Both solid and liquid phases produced metal borides with different levels between Cobalt, Nickel and Copper. Cobalt and Cupper successfully produced metal borides while Nickel produced only metal oxides. On the other hand Nickel and Copper produced nano-metal boride but Cobalt produced $\mathrm{CoB}_{2} \mathrm{O}_{4}$. All Cobalt, Nickel and Copper are $3 \mathrm{~d}$ metal (first raw transition metal series), but definitely the electronic configuration of the $\mathrm{d}$ orbital plays its role (please see previous publications) $[18,19]$.

\section{Acknowledgement}

Authors would like to express gratitude and appreciation to King Abdulaziz City for Science and Technology for providing the research Grant AT-34-255. Authors would also like to express thanks to King Abdulaziz University and in particular, the chemistry department for their continuous support.

\section{References}

1. Barnett C (1969) Hydrogenation of aliphatic nitriles over transition meta borides. Ind Eng Chem Prod Res Dev 8: 145-149.

2. Petit C, Pileni M (1997) Nanosize cobalt boride particles: Control of the size and properties. Journal of Magnetism and Magnetic Materials 166: 82-90.

3. Wodniecka B, Wodniecki P, Krolas K, Thome L (1986) TDPAC study of the crystallisation of amorphous Ni-B alloys produced by ion implantation. Journal of Physics F: Metal Physics 16: 1629.

4. Kher SS, Spencer JT (1992) Chemical vapor deposition precursor chemistry. 3. Formation and characterization of crystalline nickel boride thin films from the cluster-assisted deposition of polyhedral borane compounds. Chem Mater 4: 538-544.

5. Punge-Witteler B, Köster U (1988) Crystallization of NiB metallic glasses with high boron contents. Materials Science and Engineering 97: 343-346.
6. Machizaud F, Kuhnast FA, Flechon J, Auguin B, Defresne A (1981) Electron transport and kinetics of transformations in the amorphous alloy Ni66B34. J Phys France 42: 97-106.

7. Hofmann K, Kalyon N, Kapfenberger C, Lamontagne L, Zarrini S, et al. (2015) Metastable $\mathrm{Ni}_{7} \mathrm{~B}_{3}$ : A New Paramagnetic Boride from Solution Chemistry, Its Crystal Structure and Magnetic Properties. Inorg Chem 54: 10873-10877.

8. Buschow K (1977) Magnetic properties of borides. Boron and Refractory Borides. Springer 494-515.

9. Coyle T, Stone F (1964) Progress in Boron Chemistry. Pergamon NewYork USA.

10. Li Y, Fan Y, Chen Y (2003) A novel route to nanosized molybdenum boride and carbide and/or metallic molybdenum by thermo-synthesis method from $\mathrm{MoO} 3$ $\mathrm{KBH} 4$, and CCl4. Journal of Solid State Chemistry 170: 135-141.

11. Yeh C, Hsu W (2007) Preparation of MoB and MoB-MoSi2 composites by combustion synthesis in SHS mode. Journal of alloys and compounds 440: 193-198.

12. Yeh $\mathrm{C}$, Wang $\mathrm{H}$ (2010) Preparation of borides in $\mathrm{Nb}-\mathrm{B}$ and $\mathrm{Cr}-\mathrm{B}$ systems by combustion synthesis involving borothermic reduction of $\mathrm{Nb} 2 \mathrm{O} 5$ and $\mathrm{Cr} 2 \mathrm{O} 3$. Journal of Alloys and Compounds 490: 366-371.

13. Wang Y, Guang X, Cao Y, Ai X, Yang H (2010) Mechanochemical synthesis and electrochemical characterization of $\mathrm{VBx}$ as high capacity anode materials for air batteries. Journal of Alloys and Compounds 501: L12-L14.

14. Yeh C, Wang $\mathrm{H}$ (2011) Combustion synthesis of vanadium borides. Journal of Alloys and Compounds 509: 3257-3261.

15. Neel $L$ (1949) Theorie du rainage magnetique des ferromagnetiques en grains fins avec applications aux erres uites. Ann Geophys 5: 99-136.

16. Georgia C (2009) Papaefthymiou nanoparticle magnetism. Nano Today 4: 438-447.

17. Gittleman JI, Abeles B, Bozowski S (1974) Superparamagnetism and relaxation effects in granular $\mathrm{Ni}_{-} \mathrm{SiO}_{2}$ and $\mathrm{Ni}-\mathrm{Al}_{2} \mathrm{O}_{3}$ films. Physical Review B 9: 3891-3897. 
Citation: Ali AZO, Al-Masoudi, Soliyman R (2017) Nano-Metal Borides of Cobalt, Nickel and Copper. J Nanomed Nanotechnol 8: 477. doi: 10.4172/2157-7439.1000477

Page 10 of 10

18. Al-Zain Omar Ali, Al-Masoudi RS (2017) Solid and Liquid Synthetic Routes of Vanadium, Niobium and Titanium Nano-metal Borides. J Nanomed Nanotechnol 8: 466 .
19. Al-Zain Omar Ali, Al-Masoudi RS (2017) Different Synthetic Routes of Group Six (VIB) Nano-Metal Borides. J Nanomed Nanotechnol 8: 464. 